\title{
A case study of the College English Test and ethnic minority university students in China: negotiating the final hurdle
}

Bob Adamson ${ }^{1 *}$ and Beibei Xia ${ }^{2}$

\author{
* Correspondence: badamson@ied. \\ edu.hk \\ ${ }^{1}$ Department of International \\ Education and Lifelong Learning, \\ Hong Kong Institute of Education, \\ 10 Lo Ping Road, Tai Po, New \\ Territories, Hong Kong SAR \\ Full list of author information is \\ available at the end of the article
}

\begin{abstract}
The College English Test (CET) is one of the entry and exit requirements for undergraduate study for any major at universities in China. Its high status reflects the prominent role ascribed to the English language in the nation's economic development. For many students from China's 55 ethnic minority groups, the CET represents a formidable hurdle: they typically received piecemeal exposure to English, as their primary and secondary schooling was conducted in relatively underresourced areas. The paper reports the case of a university that lowered the CET entry requirements for these disadvantaged students. However, similar adjustments were not made to the exit requirements, resulting in the failure of hundreds of ethnic minority students to graduate. A subsequent court decision ruled that the university had not breached any laws. The paper discusses the questions of social justice that are posed by the university's actions in particular and by the importance attached to English in higher education in general, and concludes that there is a fine line between affirmative action and discrimination, and the university's language policy failed to take full account of the reality facing many ethnic minority students.

Keywords: English as a foreign language, testing, ethnic minority, social justice, China
\end{abstract}

\section{Background}

Language policies in education involve state authorities making important decisions that have implications for social justice (Mohanty 2009). These policies influence decisions that determine the language(s) to be taught in the curriculum, the time and resources to be allocated, and the medium of instruction to be used for the subjects across the curriculum. They therefore impact on the opportunities for linguistic minority students to access effective education that allows them to maintain their own cultural identity and to participate in the mainstream society. The factors that need to be taken into consideration in language policy-making are often complex (language rights, resources, curriculum ideologies, political and economic exigencies, societal expectations of education, and so on) and can be characterized as dilemmas rather than as problems, in that dilemmas cannot be resolved-formulating a response to a dilemma results in the creation of a new dilemma (Ogawa et al. 1999). The complexity and number of dilemmas increase exponentially when the language policy is concerned with trilingualism rather than monolingualism or bilingualism.

(C) 2011 Adamson and Xia; licensee Springer. This is an Open Access article distributed under the terms of the Creative Commons Attribution License (http://creativecommons.org/licenses/by/2.0), which permits unrestricted use, distribution, and reproduction in any medium, provided the original work is properly cited. 
The focus of this paper is a policy established by a tertiary institution in China concerning the English language requirements for admission and graduation to be attained by non-English majors, and the implications of this policy for ethnic minority students. Unlike their majority Han counterparts who studied only Chinese (oral Putonghua and standard written Chinese) and English, these students have experienced trilingualism in their primary and secondary education, studying their mother tongue, Chinese and English-since 2002, English has also been taught in primary schools, where circumstances permit (Lam 2007). However, many ethnic minority students come from low-resourced areas where English provision is difficult. Given the importance of English for entrance into and graduation from tertiary institutions in China (Adamson 2004; Lam 2005, 2007), these students could easily find themselves in a disadvantaged position when competing with Han students for access to the limited places available in higher education and when they seek to meet all the requirements to complete their studies. The issues surrounding access to and graduation from tertiary education create dilemmas, as English can be socially divisive. As Skutnabb-Kangas et al. (2009: 327) argue:

What needs to be resisted and counteracted is policies that privilege English at the expense of other languages. English opens doors, yes, but it closes others. English is an open sesame for some people and some purposes, but it serves to condemn others to poverty and oblivion.

This paper is a documentary study of a specific university's language policy. While this university's policy is typical of those adopted by many tertiary institutions in China, it is noteworthy in that it gave rise to a court case challenging the policy. The paper is framed around issues of social equity and justice, and draws upon six questions proposed by Tollefson (2002, pp.13-14) for analyzing language in education policies in terms of the impact on the language rights of minority groups:

1. What are the major forces affecting language policies in education and how do these forces constrain policies and public discussion of policy alternatives?

2. How do state authorities use educational language policies to manage access to language rights and language education, and what are the consequences of specific state programmes and policies for language minority communities?

3. How do state authorities use language policy for the purpose of political and cultural governance?

4. How do language policies in education help to create, reduce or sustain political conflicts among different ethno-linguistic groups?

5. How are local policies and programmes in language education affected by global processes such as colonialism, decolonisation, the spread of English and the growth of the integrated capitalist economy?

6. How can indigenous peoples and other language minorities develop educational policies and programmes that serve their social and linguistic needs, in the face of significant pressure exerted by more powerful social and ethno-linguistic groups?

The paper begins by reviewing the role and status of ethnic minority languages, Chinese and English in education policies and practices in China. It then focuses on the 
English language requirements for university entrance and graduation-the language policy at the heart of the controversy in the individual institution. The following sections present the details of the controversy, and addresses the six questions outlined above. The paper concludes by discussing the implications of the policy for social equity.

\section{Language education policies for ethnic minorities in China}

China has 55 official ethnic minority groups numbering approximately 106 million people (China National Commission for UNESCO 2004). They tend to be located in the peripheral regions of the country, often in remote, economically-underdeveloped rural areas far from the more affluent eastern seaboard. Some of the groups are assimilated into the mainstream culture; others have preserved a strong sense of distinct identity while maintaining a high degree of engagement with the Hans; other groups have tended to resist what they consider to be Han imperialism (Adamson \& Feng 2009). Language education policies for the ethnic minority groups have varied over time and according to the particular politics of a locality (as regions have considerable autonomy)-the ethnic minority language has either been supported and cultivated in the education system or suppressed (Lam 2005; Adamson \& Feng 2009). Currently, as noted above, national language education policies seek to foster trilingualism in ethnic minority students: the minority language, Chinese and English. In regions where trilingualism is promoted in a supportive manner, the minority language is taught in primary schools (though it is not usually taught higher in the system) in order to preserve the cultural identity of the students. Chinese, the national language, is taught for social, political and economic unity, and proficiency is crucial for ethnic minority students to progress in secondary schools, where they would usually join students from other minorities and Han students, and where Chinese is the medium of instruction as well as the lingua franca for social interaction (Adamson \& Feng 2009). English is taught from Primary 3 as a means to facilitate the international economic modernization of China.

The linguistic pressure on minority students arises from the need to develop competence in Chinese in order to access secondary education, and English in order to access tertiary education. The latter language is particularly problematic for minority students. While in some Chinese cities, English is the medium of instruction for mathematics, science and other subjects in selected secondary schools and (in some experimental projects) for primary education, and there are booming markets in private tuition and evening schools for children and adults, and in books, magazines, on-line learning and educational resources, ethnic minority students, being located in more remote areas and belonging to lower socio-economic groups, are generally unable to enroll in elite schools or to afford supplementary resources. English has been introduced haphazardly in the schools they attend, depending upon the availability of resources and particularly of qualified teachers. A common trend is for schools to recruit Putonghua-speaking teachers of English in the absence of teachers able to use the local ethnic language to teach the subject, which means that the students are learning their third language through their second language (Feng 2007; Adamson \& Feng 2009). These constraints have implications for the opportunities for ethnic minority students to gain admission to higher education. 


\section{Entrance requirements in English for admission to higher education}

Competence in English has been a requirement for admission to higher education since 1978, and, since 1984, it has been one of the subjects that make up the College Entrance Examination. A written English test is compulsory for all students who wish to gain a place at university. (Scores from oral examinations are included in the total score and serve only as a reference for potential English majors and other relevant specialisms.) The weighting of the English test in the overall College Entrance Examination has been increased over the past two decades from 100 points to 120 points in the early 1990s, and later to 150 points (Jin \& Cortazzi 2003). The current allocation of 150 points is out of a total of 750 points in the national test paper. In some provinces and municipalities that are authorized to set their own College Entrance Examination test papers, English accounts for a higher proportion of the total score. For instance, the weighting of English is 150 out of 630 points in Shanghai and 120 out of 480 points in Jiangsu Province.

The College English Test (CET) is a national examination administered by the Ministry of Education that was established in 1987. Its official purpose is to evaluate objectively and accurately the English proficiency of non-English majors in institutions of higher learning in China, in order to improve the quality of English teaching provided for these students (National College English Testing Committee 2006, p.3). A battery of College English Tests is conducted throughout the country under the administration of the National College English Testing Committee. There are six progressive bands in the national College English Teaching Syllabus published in 1999. The CET Band 4 (CET-4) is designed for second-year students who have finished the College English Band 1 to Band 4 syllabus and the CET Band 6 (CET-6) for third-year students who have completed Band 5 to Band 6. Three major phases are discernible in the historical development of the CET (Zheng \& Cheng 2008; Chen \& Klenowski 2009).

CET-4 was initiated in September 1987, and CET-6 in January 1989. Fundamental components of the test were laid out in the first decade. The test scores were based on a 100-point scale, of which a score of 60 points was a passing grade. Certificates were issued by the Department of Higher Education in the Ministry of Education. For those whose score was 80 or above, "Excellent" was recorded on the certificate. The second phase, 1997-2005, witnessed test format changes. In 1997, dictation was added to the listening section, and translation from English to Chinese in the reading part. In 1999, a College English Test-Spoken English Test (CET-SET) was introduced to examine students' oral communication ability on familiar topics. The CET-SET was available to students who had passed CET-4 with a score of 80 or above, or CET-6 with a score of 75 or above. In the third phase, CET was revamped in terms of test content, format and scoring system in 2006. The most remarkable change made in this stage was the elimination of the distinction between pass and fail. As of January 2005, a full score of 710 was adopted in the CET score report system. Instead of a certificate, students who score above 220 are awarded a transcript issued by the National CET-4 and CET-6 Commission on behalf of the Department of Higher Education of the National Ministry of Education (National College English Testing Committee 2006). A computerbased CET was trialled by 50 higher education institutions for the first time on 21 December, 2008. Compared with the traditional written test, the computer-based CET makes full use of multi-media, placing more emphasis on the listening section. The 
adoption of such technology is likely to mark a new era in the development of the CET.

Statistics show that CET has ranked as the largest test of English as a foreign language in the world (Cheng 2008; Zheng \& Cheng 2008). CET-4 and CET-6 are held twice annually. In 1987, the number of students who took part in the first CET-4 stood at 100,000. By 2006, this number had skyrocketed to 13,000,000 (Zheng \& Cheng 2008). To make the numbers more manageable, from the second half of 2006, CET was restricted to college students, and was no longer open to the public. Even under these circumstances, about 2 million students sit for CET every year.

CET administrators claim the test has high reliability and validity (Cheng 2008; Yang \& Weir 2001; Zheng \& Cheng 2008). Its credibility has bestowed high status. At the institution level, the passing rate on the CET is often regarded as one of the criteria to judge the prestige of a university (Cheng 2008) and CET results are regarded as the main indicator of the quality of English teaching (Zhu 2003). For college students, good performance in these tests represents the key to academic success as well as affecting their life chances in general (Cheng 2008). CET is seen as a passport to better-paid employment in business trading firms or joint ventures in China's increasingly competitive job market (Pang et al. 2002).

\section{Language policies on university admission and graduation}

The analysis in this section is concerned with the language policies relating to admission and graduation of a university located in a major city in central China. This university is listed in the State 211 Project, which means that it has been identified as a key institution to be upgraded to elite status nationally and to world-class standards in terms of teaching and research in some of its discipline areas, and is placed under the direct administration of the Ministry of Education by the authority of the State Council. Although centrally administered, the university has a high degree of autonomy according to higher education reforms instituted in the early 1990s (Chinese Communist Party Central Committee 1993). These reforms are part of a transformation of China's higher education system to gear it to meet the needs of a market economy (Hu 2010).

The university conforms to the preferential policies for ethnic minority students set by the state and provincial governments. According to the national policy (Ministry of Education of the Peoples' Republic of China 2009), provincial committees controlling university admission are authorized to award ethnic minority students from remote areas a bonus of up to 20 marks in the College Entrance Examination. In this specific case, the Provincial Education Bureau stipulated that ethnic minority students could be given 10 awarded marks, and the individual university would have the right to review each case and ultimately decide whether the students would be enrolled or not.

For graduation, a large number of higher education institutions pursue the policy of "no CET-4 certificate, no Bachelor's degree" (Pang et al. 2002; Cheng 2008). This language policy is formulated by individual institutions-the Ministry of Education has never made it a requirement that performance in CET should be linked with degree conferral. Indeed, with the introduction of the new system in 2005, the Ministry of Education tended to play down the role of CET in graduation requirements, as it had, to some extent, become overemphasized. Nonetheless, the cachet attached to English competence meant that many higher education institutions maintained the linkage. 
The university takes the view that a qualified university graduate from a key university should possess a certain benchmarked level of English competence. Presumably on the grounds that CET is viewed as the most mature, most valid and most widely recognized English test in this context in China, the university adopted it to assess students' English proficiency, and, consequently, their eligibility for degree conferral. The current policy of the university concerning degree conferral is set out under the terms of its Interim Provisions for Bachelor's Degree Conferral, reviewed and passed by the $4^{\text {th }}$ Presidential Meeting in 2005. Article 5.4 explicitly states "a Bachelor's Degree cannot be conferred upon students whose foreign language proficiency does not meet the requirements of the University." This English proficiency requirement is published by the university in the Notice on Degree Conferral Affairs each year. On 3 June, 2008, the Academic Affairs Office of the university issued the Foreign Language Requirements of Degree Conferral to 2008 Full-time Graduates. Article 1.2 stated that "For non-English majors, CET serves as the criterion of English proficiency of Bachelor's Degree conferral". Article 2.1 further stipulated that "For full-time graduates, a minimum score of 50 (the percentage system) or 355 (710-score-system) is the English proficiency requirement of degree conferral".

To enable the students at the university to pass CET-4 before graduation, the university allows non-English majors six attempts at the test. Students first sit CET-4 in their second year in the university. If they fail, they can re-take the test up to five times. The minimum score of 355 in the new CET-4 required for conferral of a Bachelor's degree under the terms of the university policy is, on the face of it, relatively undemanding, but other forms of language support, such as courses to develop English competence or courses delivered through the medium of English, are scarce. In the event, since the formulation of the policy incorporating the language requirement, hundreds of students in the university did not graduate from their undergraduate programmes because of their failure in CET-4. In 2005 alone, for instance, some 600 completing students out of a total enrollment of 36,000 undergraduates were issued a statement by the university instead of a Bachelor's degree certificate. The statement made it clear that students were not awarded a degree as they had not met the minimum requirements of English proficiency. Among the 600 graduates, a large number were ethnic minority students from Inner Mongolia, Xinjiang and Ningxia.

\section{Lawsuit over degree conferral}

The link between CET and degree conferral triggered a lawsuit against the university. On completion of their study in 2005, five students appealed to the Ministry of Education for "administrative reconsideration" on the grounds that they had been denied their Bachelor's degree due to their failure in CET-4. The Ministry of Education rejected the appeal because the matter did not fall within the scope of such reviews. The graduates then sued the university, alleging violation of The Regulations of the People's Republic of China on Academic Degrees (Ministry of Education of the Peoples' Republic of China 2004), which was adopted at the $13^{\text {th }}$ Session of the Standing Committee of the Fifth National People's Congress on 12 February 1980 and amended at the $11^{\text {th }}$ Session of the Standing Committee of the Tenth National People's Congress on 28 August 2004. Article 4 of these Regulations states "The bachelor's degree shall be conferred on graduates from institutions of higher learning who have good 
academic records and have attained the following academic standards: (1) having a relatively good grasp of basic theories, specialized knowledge and basic skills in the discipline concerned; and (2) having initially acquired the ability to undertake scientific research or to engage in a special technical work." The students argued that the regulations do not imply that a CET certificate is required for degree conferral.

The court decided in favour of the university on the basis that decisions regarding degree conferral are a matter of institutional autonomy guaranteed by law (see Wuhan Intermediate People's Court 2006). Article 11 of Higher Education Law of the People's Republic of China (Ministry of Education of the Peoples' Republic of China 1999) explicitly states that "Institutions of higher learning should be geared to the needs of society, run independently and practise democratic management in accordance with law". In addition, Article 25 of the Provisional Measures of the People's Republic of China on Academic Degrees (Ministry of Education of the Peoples' Republic of China 1981) stipulates, "Degree-conferring units may, in accordance with these regulations, make rules for the degree-conferring work of their own units." Therefore, the court decided, making CET a prerequisite of degree conferral did not violate the law, especially as the university had appropriately fulfilled their obligation to make known the requirement to students.

\section{Discussion}

At the beginning of this paper, we outlined six questions posed by Tollefson (2002) concerning the impact of language in education policies on the linguistic rights of ethnic minority groups. In this section, the discussion will focus on each question in respect of the specific language policy pursued by the university.

\section{Major forces affecting the language policy}

The policy reflects the importance attached to English in China in the preparation of human resources for the economic development of the country. English competence is a crucial determinant for securing employment, promotion, and overseas experiences; it is also seen as facilitative for China's staging of international events such as the Beijing Olympic Games in 2008 and the Shanghai World Expo in 2010, and for the nation's diplomatic, cultural and commercial interactions with other countries (Lam 2002; Zhu 2003; Adamson 2004; Feng 2005; Cheng 2008; Simpson 2008). The importance of the roles and status accorded to the language in contemporary China has "reached unprecedented heights, although fundamental cultural and political tensions remain” (Gil \& Adamson 2011: 30).

These tensions include the disadvantaging of ethnic minority students because of their limited access to English, which authorities have sought to mitigate by affirmative action in university admissions. However, the strength of the status of English, its embedding in many facets of society in China, and the use of benchmarks such as the CET for assuring the desirable attributes of graduates all constrain the flexibility of authorities in allowing waivers to the graduation requirements in English.

\section{Policies, language rights and consequences}

The university language policy reflects broader attitudes underpinning language in education policies for ethnic minority groups, which either tolerates or suppresses the 
minority languages in the interests of national cohesion through the promotion of Chinese, and international economic development through the promotion of English (Adamson \& Feng 2009). Wittingly or unwittingly, by ignoring the value of minority languages, the language policy reinforces the low status of those languages in state institutions such as universities and therefore in society as a whole. A further consequence of the policy is that, by denying graduation purely on the grounds of poor English proficiency, it limits the chances of ethnic minority students (and other groups that were disadvantaged in their learning of English) to access the socio-economic benefits that generally accrue to university graduates.

\section{Political and cultural governance}

Language policies are facilitated and institutionalized by systemic tools. In this case, the tools are the regulations for admission and for graduation, which are controlled either by the central government or by the universities under the administration of the Ministry of Education, and the national CET assessment framework. These tools create a narrow linguistic profile of the desired graduates of elite universities, thereby establishing a hierarchical structure that privileges competence in English (and Chinese), and exerts a subtractive effect on the minority languages and, by extension, their culture. The comparatively low economic capital associated with most ethnic minority languages can lead to their diminished presence in the school curriculum and thus makes the preservation and vitalization of minority cultures more difficult.

\section{Political conflicts}

The language policy is controversial and divisive. Conflicts arise partly because the policy (through omission) does not value the ethnic minority language, and partly because it is incoherent. Ethnic minority students receive preferential treatment at entry, but not upon graduation, and the expectation that their English competence should improve to the extent that they fulfil standardized graduation requirements-which might be viewed as setting a level playing field for all-is unrealistic. As a result, the policy tends to favour the Han students, who are more likely to have received better access to English prior to entering university.

The conflict is symptomatic of broader tensions between the Han and ethnic minorities, which have centred around the issues of cultural diversity, political control and access to economic resources (Adamson \& Feng 2009).

\section{Global processes and the integrated capitalist economy}

Located in the Expanding Circle of Kachru's (1985) “three circles" model, China's relationship with the English language has been historically ambivalent: at times, English has been seen as threatening national integrity; at other times, it has been viewed as a utilitarian conduit for strengthening China's presence and power in the world (Adamson 2004). The impact of globalization and the integrated capitalist economy on higher education includes the promotion of the English language, as university curricula are closely aligned with the economic needs of the state.

The higher status thus accorded to English can prove detrimental to lower status languages in formal education, as well as putting pressure on the capacity of poorer regions to provide access for schoolchildren to effective English teaching. 


\section{Supportive ethnic minority language policies}

Primary schools in ethnic minority-dominated regions of China often have trilingual policies: the students learn their mother tongue, Chinese and (from Primary 3) English. This support is not extensively maintained throughout the school system. Generally speaking, the minority language is dropped quite early, as students need to learn through the medium of Chinese and develop their English competence in order to progress through secondary and tertiary education (Adamson \& Feng 2009). There is no indication of support for ethnic minority languages in the university policy discussed in this case study.

\section{Conclusion}

The university's degree conferral policy provides a microcosmic instance of the tensions that are created by what Blachford and Jones (2011) identify as a dilemma between policy ideals and contextual realities. The problems arising from the university policy are an extension of the difficulties created by the trilingual education policy in China, which envisages primary school students studying their mother tongue, Chinese and English. Ideally, these three languages will bolster the students' sense of cultural identity as well as their access to mainstream education and economic opportunities, and so the policy can be seen as collaborative and ameliorative, rather than coercive and destructive (Adamson \& Feng 2009).

The reality, however, is that the learning of English tends to flourish in regions of China where students have the chance to interact with the language through exposure to rich resources, which disadvantages many ethnic minority groups. Minority students who have succeeded, against the odds, in reaching an elite university (albeit with assistance, in many cases, through affirmative action) find themselves tripped by the final hurdle-a test in a language that is an alien intruder, linguistically and culturally, and that may have little or no relevance to the student's major. Despite the good intentions of the affirmative action, the policy reality-as with many language policies affecting the ethnic minority groups-is, as Blachford and Jones (2011, p.229) aver, "a highly uneven playing field, far divorced from the policy ideal passed in Beijing".

If the trilingual policy is to achieve its goal of equality of opportunity, and if ethnic minority students are not to fall at the final hurdle at university, there needs to be a comprehensive review that takes into account the realities of the rural schools and communities where the linguistic foundations are laid. While the court's ruling on the students' challenge to the imposition of CET scores as a graduation requirement was legally sound, the rationale behind such practices needs re-examination by policymakers so that language policies become emancipatory rather than reinforcing inequality. Key issues for policy-makers to consider include the status accorded to the English language in the education system, and the standards that graduates are expected to achieve in the CET, as well as the status accorded to ethnic minority languages in the education system. A more equitable system requires a balanced approach that might include toning down the expectations in respect of English and enhancing the commitment to ethnic minority languages through explicit policies and institutional structures. 


\section{Authors' contributions}

Both BA and BX contributed to the conception, design, collection, analysis and interpretation of data. Both authors read and approved the final manuscript.

\section{Authors' Information}

Bob Adamson is Professor of Curriculum Studies at Hong Kong Institute of Education. He researches and publishes in the fields of English language teaching, teacher education, comparative education, curriculum studies and higher education. His books include China's English; Curriculum, schooling and society (with Paul Morris); Assessment reform in education (co-edited with Rita Berry); and Comparative education research approaches and methods (co-edited with Mark Bray and Mark Mason). He is currently Vice President of the Comparative Education Society of Hong Kong. Beibei Xia is an Associate Professor in the School of Foreign Languages for International Business at the Shanghai Institute of Foreign Trade, and a doctoral student in the Faculty of Languages at Hong Kong Institute of Education. Her research interests include business English, bilingual education and interpretation. She has published book chapters and journal articles in these areas. She is currently working on her doctoral thesis entitled "Understanding bilingual teaching in China's higher education: An evaluative study of a model bilingual course".

\section{Competing interests}

The authors declare that they have no competing interests.

Received: 12 April 2011 Accepted: 16 December 2011 Published: 16 December 2011

\section{References}

Adamson, Bob, and Anwei Feng. 2009. A comparison of trilingual education policies for ethnic minorities in China. Compare 39(3): 321-333.

Adamson, Bob. 2004. China's English: a history of English in Chinese education. Hong Kong: Hong Kong University Press. Blachford, Dongyan Ru, and Marion Jones. 2011. Trilingual education policy ideals and realities for the Naxi in rural Yunnan. In English language education across Greater China, ed. Anwei Feng. 228-259. Clevedon, UK: Multilingual Matters.

Chen, Qiuxian, and Valentina Klenowski. 2009. Assessment and curriculum reform in China: the College English Test and tertiary English as a foreign language education. Proceedings of the 2008 AARE International Education Conference. http://eprints.qut.edu.au/28346/1/c28346.pdf. Accessed 8 April 2011.

Cheng, Liying. 2008. The key to success: English language testing in China. Language Testing 25(1): 15-37.

China National Commission for UNESCO. 2004. Education development in China (2004). Beijing: China National Commission for UNESCO.

Chinese Communist Party Central Committee. 1993. Outline for reform and development of education in China. Beijing: People's Press.

Feng, Anwei. 2005. Bilingualism for the Minor or for the Major: an evaluative analysis of parallel conceptions. International Journal of Bilingual Education and Bilingualism 8(6): 529-551.

Feng, Anwei. 2007. Intercultural space for bilingual education. In Bilingual education in China, ed. Anwei Feng. 259-286. Clevedon, UK: Multilingual Matters.

Gil, Jeffrey, and Bob Adamson. 2011. The English language in China: a sociolinguistic profile. In English language education across Greater China, ed. Anwei Feng. 23-45. Clevedon, UK: Multilingual Matters.

$\mathrm{Hu}$, Jianhua. 2010. Reforms in higher education: a view from China. In Educational reforms in Russia and China at the turn of the 21st century: a comparative analysis, ed. Nina Ye Borevskaya, Borisenkov VP, Xiaoman Zhu. 46-49. Hong Kong: Comparatiev Education Research Centre, The University of Hong Kong.

Jin, Lixian, and Martin Cortazzi. 2003. English language teaching in China: A bridge to the future. In English language teaching in East Asia today: Changing policies and practices, ed. Wah Kam Ho, Ruth Yeang Lam Wong. 131-146. Singapore: Eastern Universities Press.

Kachru Braj, B. 1985. Standards, codification and sociolinguistic realism: the English language in the outer circle. In English in the world: Teaching and learning the language and literature, ed. Randolph Quirk, Henry G. 11-30. Widdowson, Cambridge: Cambridge University Press.

Lam, Agnes Shun Ling. 2002. English in education in China: Policy changes and learners' experiences. World Englishes $21(2)$ : $245-256$.

Lam, Agnes Shun Ling. 2005. Language education in China: policy and experience from 1949. Hong Kong: Hong Kong University Press.

Lam, Agnes Shun Ling. 2007. Bilingual or multilingual education in China: policy and learner experience. In Bilingual education in China, ed. Anwei Feng. 13-33. Clevedon, UK: Multilingual Matters.

Ministry of Education of the Peoples' Republic of China. 1981. Provisional Measures of the People's Republic of China on Academic Degrees. http://www.moe.edu.cn/edoas/website18/97/info5897.htm. Accessed 20 April 2009.

Ministry of Education of the Peoples' Republic of China. 1999. Higher Education Law of the People's Republic of China. http://www.moe.edu.cn/edoas/website18/en/laws_h.htm. Accessed 20 April 2009.

Ministry of Education of the Peoples' Republic of China. 2004. The Regulations of the People's Republic of China on Academic Degrees. http://www.moe.edu.cn/edoas/website18/29/info1429.htm. Accessed 20 April 2009.

Ministry of Education of the Peoples' Republic of China. 2009. Notice on 2009 recruitment work of institutions of higher learning. http://202.205.177.9/edoas/website18/65/info1237531362588765.htm. Accessed 8 April 2011.

Mohanty Ajit, K. 2009. Multilingual education: a bridge too far? In Social justice through multilingual education, ed. Tove Skutnabb-Kangas, Robert Phillipson, Aijt K Mohanty, Minati Panda. 3-15. Bristol: Multilingual Matters.

National College English Testing Committee. 2006. Syllabus for College English Test Band 4. Shanghai: Shanghai Foreign Language Education Press.

Ogawa, Rodney, RL Crowson, and Ellen Goldring. 1999. Enduring dilemmas in school organization. In Handbook of research on educational administration, ed. Joseph Murphy, Karen Seashore. 277-295. Louis, San Francisco: Jossey Bass. 
Pang, Jixian, Xing Zhou, and Zheng Fu. 2002. English for international trade: China enters the WTO. World Englishes 21(2): 201-216.

Simpson Steven, T. 2008. Western EFL teachers and East-West classroom-culture conflicts. RELC Journal 39(3): 381-394.

Skutnabb-Kangas, Tove, Robert Phillipson, Minati Panda, and Ajit Mohanty. 2009. Multilingual education concepts, goals, needs and expense: English for all or achieving justice? In Social justice through multilingual education, ed. Tove Skutnabb-Kangas, Robert Phillipson, Ajit K Mohanty, Minati Panda. 320-344. Bristol: Multilingual Matters.

Tollefson James, W. 2002. Introduction: critical issues in educational language policy. In Language policies in education: critical issues, ed. James W Tollefson. 3-15. Mahwah, NJ: Lawrence Erlbaum Associates, Inc.

Wuhan Intermediate People's Court. 2006. Administrative Written Judgement No. 60. http://whfy.chinacourt.org/public/detail. php?id=2778. Accessed 5 June, 2011.

Yang, Huizhong, and Cyril Weir. 2001. Validation study of the National College English Test. Shanghai: Shanghai Foreign Language Education Press, 3.

Zheng, Ying, and Liying Cheng. 2008. College English Test (CET) in China. Language Testing 25(3): 408-417.

Zhu, Huimin. 2003. Globalization and new ELT challenges in China. English Today 19(4): 36-41.

doi:10.1186/10.1186/2191-5059-1-1

Cite this article as: Adamson and Xia: A case study of the College English Test and ethnic minority university students in China: negotiating the final hurdle. Multilingual Education 2011 1:1.

\section{Submit your manuscript to a SpringerOpen ${ }^{\circ}$} journal and benefit from:

- Convenient online submission

- Rigorous peer review

- Immediate publication on acceptance

- Open access: articles freely available online

- High visibility within the field

- Retaining the copyright to your article

Submit your next manuscript at $\gg$ springeropen.com 